\title{
Influence of Esterification on the Water Absorption Property of Single Abaca Fiber
}

\author{
RAMADEVI PUNYAMURTHY ${ }^{\mathrm{a}}$, DHANALAKSHMI SAMPATHKUMAR ${ }^{\mathrm{a}}$, \\ ${\text { BASAVARAJU BENNEHALLI }{ }^{\mathrm{b} *} \text { and CHIKKOL V. SRINIVASA }}^{\mathrm{c}}$
}

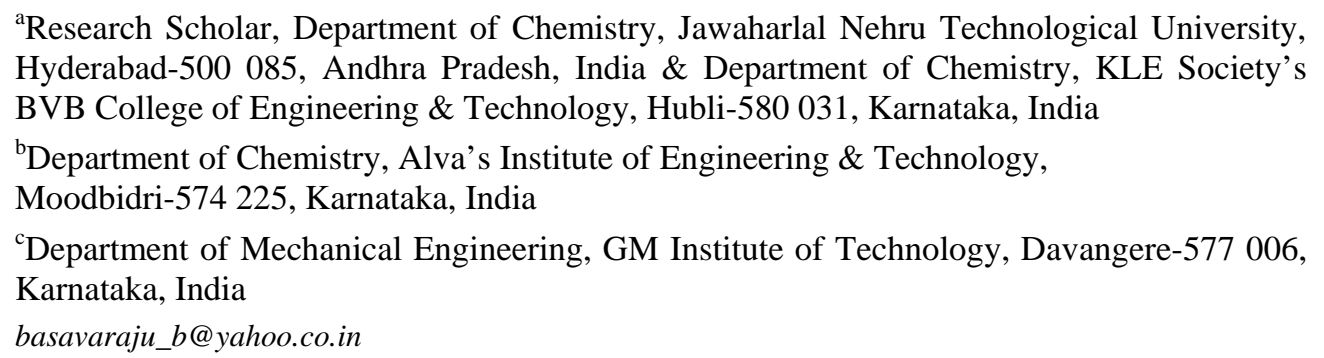

Received 3 September 2012 / Accepted 19 September 2012

\begin{abstract}
Environmentally valuable composites would be made by replacing synthetic fibers with various types of natural cellulose fibers. The most significant factor in finding good fiber reinforcement in the composite is the strength of the bond between matrix polymer and fiber. Due to the presence of hydroxide and other polar groups in various constituents of natural fiber, the moisture absorption is high which leads to poor wettability and weak interfacial bonding between fibers and the more hydrophobic matrices. Therefore, it is necessary to impart hydrophobic nature to the natural fibers by suitable chemical treatments in order to develop composites with better mechanical properties. In the present work, the effect of esterification on moisture absorption of single abaca fiber has been investigated. It was observed that the esterification process drastically reduced the moisture uptake of fibers. Acrylic acid treated abaca fiber showed about 32.87, 32.53, 50.76 and 39.01\% lower moisture absorption than untreated fiber in pond water, river water, borewell water and sea water respectively.
\end{abstract}

Keywords: Natural fiber, Moisture absorption, Chemical treatment, Abaca fiber, Acrylic acid, Pond water

\section{Introduction}

Due to the environmental awareness and Government policies, composite industries are looking for the new materials which are environmentally friendly. Natural lignocellulosic fibers have been receiving considerable attention as substitute for ever depleting petroleum sources. This is because the natural fibers exhibit many advantageous properties such as low density, low cost, high stiffness, biodegradability, reduced energy consumption, high degree of flexibility during processing and it is a renewable source. These natural fibers include sisal, 
jute, hemp, abaca, coir and many others. Some of the potential applications of natural fibers such as flax, jute, banana, sisal, pineapple leaf fiber are in textile, packaging, low-cost housing, paper manufacturing industries, and other general applications. In addition, plant fibers can also be used to produce fuel, chemicals, enzymes and food.

Synthetic fiber-reinforced composites offer many benefits such as high strength, light weight, water resistance, chemical resistance, high durability, electrical resistance, fire resistance and corrosion resistance. In fiber composites, fibers are used as reinforcement in matrix resin and offer the greatest strength of a structural material. Although synthetic fibers such as glass fibers, carbon fibers and aramid are high performance materials, they are less biodegradable and are sourced from non-renewable resources. Therefore, the use of natural fibers may bring environmental benefits as well as cost benefits.

Natural fibers are sourced from plants which are renewable in origin and they can be easily biodegraded. Many researchers and technologists have utilized natural fibers in the fabrication of composites. It has been found that these natural fiber-reinforced composites possess good electrical resistance, chemical resistance, good thermal and acoustic insulating properties, and high resistance to fracture.

Ample of studies on composites made by reinforcing natural fibers such as straw, banana, abaca, areca, hemp, sisal, jute, flax, pineapple, bamboo, kenaf, bagasse have shown that lignocellulosic fibers have the prospective to be a successful reinforcement in thermoplastic and thermosetting materials ${ }^{1-17}$.

Although there have been several studies on the mechanical behavior of natural fiberreinforced composites, only few references are available on abaca fiber-reinforced composites $^{18,19}$. Abaca or banana fiber is the cellulose fiber obtained from the pseudo-stem of the banana plant (Musa Textillis) and exhibits relatively good mechanical properties ${ }^{20}$. Currently abaca fiber reinforced composites are coming into interest due to the innovative application of abaca fiber in under floor protection of passenger cars by Daimller Chrysler $^{21,22}$. It is described that abaca fiber has high tensile strength, resistant to rotting and its specific flexural strength is nearer to that of glass fiber ${ }^{23}$.

Several considerations have to be taken into account in the design of natural fiber composites. Two major factors that limit the large scale production of natural fiber composites are the strength of natural fiber composites and water absorption of composites. The strength of natural fiber reinforced composites is very low compared to glass. This is due to the inaptness between the fiber and the resin matrix. Natural fibers absorb water from the air and the environment. This absorption deforms the surface of the composites by swelling and creating voids. The deformation lowers the strength of composites and increases the mass of composites.

The irregularities of the fiber surface play an important role in the mechanical interlocking between the fiber and the matrix. Surface characteristics, such as wetting, adhesion, surface tension, or porosity of fibers, can be improved upon chemical modification $^{24}$. The moisture absorbed by the fibers can be reduced by chemical modifications of fibers such as alkali treatment, acetylation, methylation, cyanoethylation, benzoylation, permanganate treatment and acrylation ${ }^{25-29}$.

Many attempts have been made to study the properties of chemically treated natural fiber-reinforced polymer composites. But only a few studies on the mechanical properties of acrylic acid treated natural fiber-reinforced composite materials were reported. The Flexural properties, storage modulus and the glass transition temperature of composites made by 
reinforcing acrylic acid treated natural fiber found to improve. Also, water absorption of polymer composites made by reinforcing acrylic acid treated natural fibers found to decrease when compared to water absorption of untreated natural fibers composite materials ${ }^{7,18,30}$. acrylation is a method for reducing the hygroscopicity of the natural fiber. The polymer hydroxyl group of the cell wall reacts with a carboxylic group of acrylic acid to yield an ester so that fiber becomes more hydrophobic in nature.

At present there is no information on the water absorption studies of acrylated single natural fiber. A better understanding of moisture absorption property of fibers will help to develop a productive use of fibers in composite materials. Therefore, this study seeks to determine the moisture absorption characteristic of acrylic acid treated single abaca fiber.

\section{Experimental}

Abaca fibers were obtained from the Maruti Peach Finishing Company, Tirupur, Chennai, India and Analytical grade reagents were purchased from Qualigens Company and used as received.

\section{Extractible content}

$5 \mathrm{~g}$ of air dried abaca fiber was placed in a Soxhlet extraction unit. A mixture of ethanol and toluene was used as solvent and extraction process continued for a period of five hours. After extraction, the sample was rinsed with ethanol and hot water and dried up to constant weight at the temperature of $60{ }^{\circ} \mathrm{C}$. The extractible were calculated as a percentage of the oven dried test sample.

\section{Lignin content}

$2 \mathrm{~g}$ of Extracted sample was placed in a flask, and $15 \mathrm{~mL}$ of $72 \%$ sulphuric acid was added. The mixture was stirred frequently for three hours at $25{ }^{\circ} \mathrm{C}$ and $200 \mathrm{~mL}$ of distilled water was added to the mixture. Then the mixture was boiled for two hours and cooled. After $24 \mathrm{~h}$, the lignin was transferred to the crucible and washed with hot water repeatedly until becoming acid free. The collected lignin was dried at $105{ }^{\circ} \mathrm{C}$ and cooled down in a desiccator and weighed. The drying and weighing were repeated until constant weight was obtained.

\section{Holocellulose content}

$3 \mathrm{~g}$ of Air dried abaca fiber was weighed and placed in an erlenmeyer flask and then, $160 \mathrm{~mL}$ of distilled water, $0.5 \mathrm{~mL}$ of glacial acetic acid and $1.5 \mathrm{~g}$ of sodium chloride were added successively. The flask was placed in a water bath and heated up to $75{ }^{\circ} \mathrm{C}$ for an hour and then an additional $0.5 \mathrm{~mL}$ of glacial acetic acid and $1.5 \mathrm{~g}$ of sodium chloride were added. The additions of acetic acid and sodium chloride were repeated two times hourly. The flask was placed in an ice bath and cooled down to below $10{ }^{\circ} \mathrm{C}$. The holocellulose was filtered and washed with acetone, ethanol and water respectively. After the washings, the sample was dried in an oven at $105^{\circ} \mathrm{C}$ before weighing.

\section{$\alpha$-Cellulose content}

$2 \mathrm{~g}$ of Holocellulose was placed in a beaker and $10 \mathrm{~mL}$ of $17.5 \%$ sodium hydroxide solution was added. The fibers were stirred up by glass rod so that they could be soaked with sodium hydroxide solution vigorously. Then the sodium hydroxide solution was added to the mixture periodically (once in every five minutes) for half an hour and the mixture temperature was kept at $20{ }^{\circ} \mathrm{C}$. About $33 \mathrm{~mL}$ of distilled water was added in the beaker and 
kept it for an hour. The holocellulose residue was filtered and transferred to the crucible and washed with $100 \mathrm{~mL}$ of $8.3 \%$ sodium hydroxide, $200 \mathrm{~mL}$ of distilled water, $15 \mathrm{~mL}$ of $10 \%$ acetic acid and with water, successively. The crucible with $\alpha$-cellulose was dried and weighed.

\section{Hemicellulose content}

The hemicellulose content of abaca fiber was determined by calculating the difference between holocellulose and $\alpha$-cellulose ${ }^{5,19}$.

\section{Alkali treatment of fiber}

The fibers are first dewaxed by soaking in 1:2 mixtures of ethanol and benzene for $72 \mathrm{~h}$, followed by washing with deionised water and then air dried. The dewaxed fibers were immersed in 5, 10, 15\% $\mathrm{NaOH}$ solution, where the total volume of the solution was 15 times the weight of the fibers. The fibers were kept in alkaline solution for $72 \mathrm{~h}$ at room temperature; they were thoroughly washed in running water and then neutralized with $2 \%$ acetic acid solution. Lastly, the fibers were washed again in running water to remove the last traces of acid sticking to it, so that the $\mathrm{pH}$ of the fibers was approximately 7 . Then, they were dried at room temperature for $48 \mathrm{~h}$ to obtain alkali-treated fibers ${ }^{5}$.

\section{Acrylic acid treatment of fiber}

Alkali treated abaca fiber was soaked in $5 \%$ acrylic acid (AA) solution at $50{ }^{\circ} \mathrm{C}$ for $1 \mathrm{~h}$, then washed with distilled water thoroughly and dried in an oven for $24 \mathrm{~h}$ at the temperature of $70{ }^{\circ} \mathrm{C}^{31}$.

\section{Water absorption studies}

The study of water absorption on untreated and acrylic acid treated fibers were carried out in water from various sources such as pond water, borewell water, river water \& sea water. The $\mathrm{pH}$ values of water samples were, pond water: 8.20 , borewell water: 7.40 river water: 7.74 , sea water: 7.76. Humidity chambers (desiccators) were set up at $100 \%$ humidity using water from various sources. The specimens were prepared from bundles of single fibers bound together. The specimens (untreated and acrylic acid treated abaca fiber) were dried in hot air oven at $60{ }^{\circ} \mathrm{C}$ for $24 \mathrm{~h}$, weighed on a balance accurate to 4 decimal places ( $\pm 0.1 \mathrm{mg}$ ) and were then placed in the humidity chamber. The humidity chamber was held at room temperature. After $24 \mathrm{~h}$, each fiber bundle was taken out of the humidity chamber and excess water was carefully mopped with filter paper. Finally, the weight of the fibers was measured and the MC was calculated by weight difference. Then again the sample is immersed in water and the same process is repeated after every $24 \mathrm{~h}$ till $2400 \mathrm{~h}$. A graph is plotted between the percentage of moisture content and square root of immersion time.

$$
M C=\frac{m_{a}-m_{d}}{m_{a}} \times 100 \%
$$

Where MC is the moisture content, $m_{a}$ is the mass of the sample after exposing to moisture and $m_{d}$ is the mass of the dry sample. More details about the technique can be found in the literature $\mathrm{e}^{5,32-34}$.

\section{Morphological study}

Scanning electron microscopic (SEM) photographs of untreated, alkali treated and acrylic acid treated abaca fibers were obtained with a JEOL JSM-T330A scanning electron microscope at the accelerating voltage of $20 \mathrm{KV}$. 


\section{Fourier transform infrared spectroscopy (FTIR)}

Fourier-transform infrared spectroscopy, model Perkin Elmer System 2000 was used to analyse the possible chemical bonding existing in the untreated and treated abaca fibers. FTIR spectra were analysed with an IR spectrophotometer with a range between $500 \mathrm{~cm}^{-1}$ and $4000 \mathrm{~cm}^{-1}$.

\section{Results and Discussion}

\section{Chemical composition of fiber}

Lignocellulosics are three-dimensional, polymeric composites made up primarily of cellulose, hemicellulose and lignin. In natural fibers, semicrystalline cellulose is the main reinforcement material. The cellulose is held together by amorphous hemicelluloses and fibers are cemented together in the plant by lignin which is commonly known as plant cell adhesive. Lignocellulosic fibers may differ in chemical composition, but have very similar properties such as flammability, thermoplasticity, moisture sorption, and degradation by acids, bases and ultraviolet radiation. All of these characteristics will result in the specific end use of lignocellulosics in composite formulation. The chemical composition of the major components of abaca fiber is listed in Table 1 . The cellulose content in the abaca fiber $(68.32 \%)$ is comparable with those of flax, jute, sisal and coir fibers ${ }^{35-37}$.

Table 1. Chemical composition (wt \%) of abaca fiber

\begin{tabular}{|c|c|c|c|c|c|}
\hline Reference & Cellulose & Hemicellulose & Lignin & $\begin{array}{l}\text { Moisture } \\
\text { content }\end{array}$ & $\begin{array}{c}\text { Ash } \\
\text { content }\end{array}$ \\
\hline Experimental & 68.32 & 17.32 & 8.5 & 0.76 & 5.10 \\
\hline Rowell et al. ${ }^{37}$ & 61.50 & 14.90 & 9.70 & -- & 4.80 \\
\hline Indicula et al. ${ }^{38}$ & $63-64$ & 19.00 & 5.00 & $10-11$ & -- \\
\hline Taj et al. ${ }^{39}$ & $56-63$ & -- & $12-13$ & $5-10$ & -- \\
\hline Satyanarayana et al. ${ }^{40}$ & 66.00 & -- & 5.00 & -- & -- \\
\hline
\end{tabular}

\section{Morphological study}

The SEM micrographs of untreated and chemically treated (alkali and acrylic acid) abaca fibers are presented in Figure 1. It can be observed that untreated abaca fiber presents a network structure in which the fibrils are bound together by hemicellulose and lignin. The SEM micrograph of untreated abaca fiber clearly demonstrates the presence of longitudinally oriented unit cells with more or less parallel orientations. The intracellular space is filled up with the binder lignin and fatty substances, which hold the unit cells firmly in a fiber. The micrograph of alkali-treated abaca fiber clearly shows a large number of pin holes or pits on the surface, which are due to the removal of fatty deposits from the fiber. A large number of globular fatty deposits lie concealed below the surface of the untreated fiber and these are not discovered by the SEM pictures of untreated fibers and are only revealed in alkali-treated fibers ${ }^{41,42}$. Figures 1 (b) and (c) designate a very fresh surface of abaca fibers.
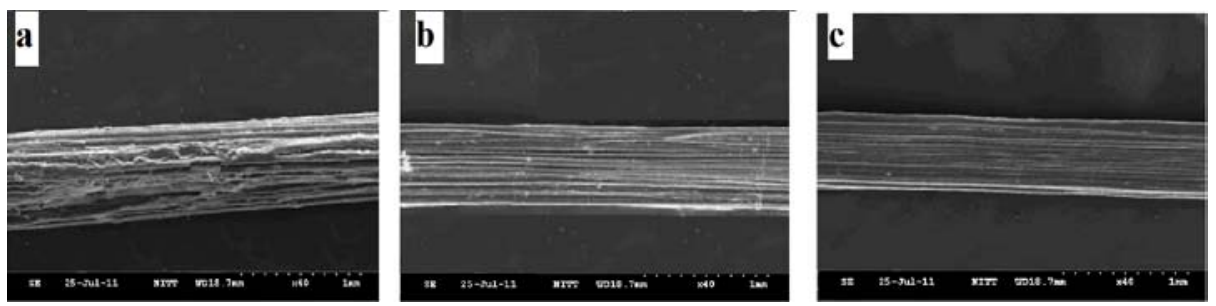

Figure 1. SEM photograph of abaca fiber: a) Untreated; b) Alkali treated, c) Acrylic acid treated 
The surface of the acrylic acid (AA) treated fiber appears to be moderately roughened by the chemical treatments. Besides, the individual ultimate fibers also show a slight separation. This is possibly due to the removal of fibers external surface layer through dissolution in sodium hydroxide and acrylic acid during the stage of treatment.

\section{IR spectra}

Chemical treatment of abaca fibers resulted in significant differences in the infrared spectra. The IR spectrum of untreated and treated abaca fiber is presented in Figure 2.
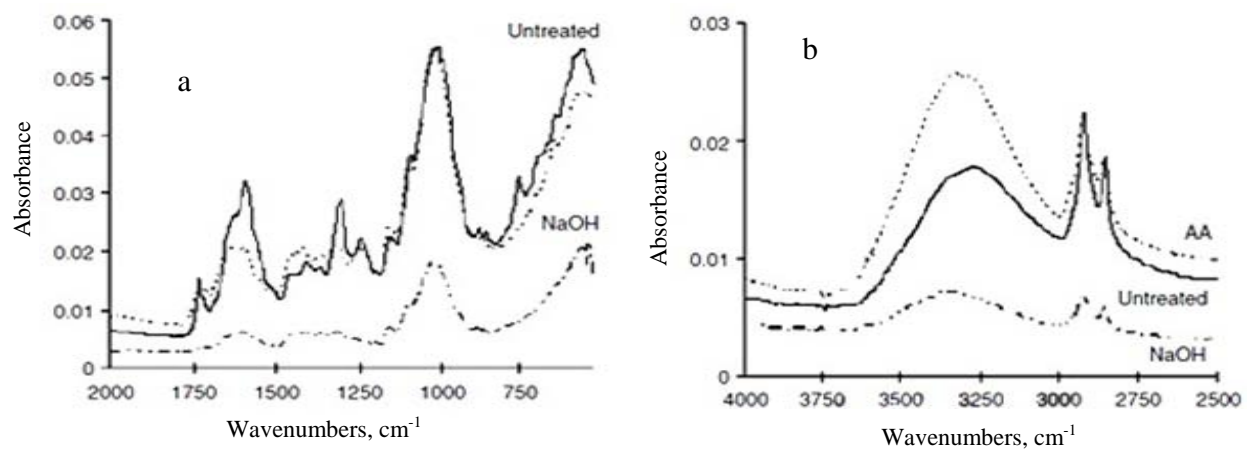

Figure 2. FTIR spectra of untreated, alkali treated and acrylic acid treated abaca fiber

The peaks obtained in IR Spectra are listed in Table 2. A huge band at $3375 \mathrm{~cm}^{-1}$ is correlated to the hydroxyl groups and the $\mathrm{O}-\mathrm{H}$ stretching vibrations present in carbohydrate (cellulose + hemicellulose) ${ }^{43}$. A band at $3350 \mathrm{~cm}^{-1}$ assigned to the alcohol group has been reduced in alkali treated fiber. This may be due to the removal of hemicellulose by alkali treatment. However, the peak at $3350 \mathrm{~cm}^{-1}$ is increased in acrylic acid treated fiber due to the hydroxyl group of the acrylic unit. A peak at $1310 \mathrm{~cm}^{-1}$ due to the alcohol group of cellulose $\mathrm{OH}$ deformation was also condensed by both acrylic acid and alkali treatments. The peaks situated at 2900 and $2825 \mathrm{~cm}^{-1}$ may be credited to the $\mathrm{CH}$ group. As expected, the peak is less marked in alkali treated fiber spectra and more in the acrylic acid treated fiber spectra because acrylic acid treatment leads to $-\mathrm{CH}_{2}$ - and - $\mathrm{CH}$ - group formation ${ }^{44}$.

Table 2. FTIR peaks position of abaca fiber

\begin{tabular}{ll}
\hline Wave number, $\mathrm{cm}^{-1}$ & FTIR peak origin \\
\hline $3250-3500$ & Hydroxyl group and bonded OH stretching \\
2900 & CH aliphatic and aromatic \\
2825 & CH aliphatic and aromatic \\
1740 & C=O stretching vibrations (carboxylic group and ester groups) \\
1600 & Lignin components \\
1300 & Alcohol group \\
1250 & Hemicellulose and pectin \\
1100 & C-O-C symmetric glycosidic stretch \\
780 & Lignin Components \\
\hline
\end{tabular}

A band at $1740 \mathrm{~cm}^{-1}$ assigned to carbonyl stretching, matching to hemicellulose was observed in both untreated and acrylic acid treated abaca fiber spectra. But the band has not been observed in the alkali treated abaca fiber spectra. The presence of the band at $1740 \mathrm{~cm}^{-1}$ is due to the ester group in acrylic acid treated fiber ${ }^{45}$. The presence of lignin in the untreated 
fiber was recognized by the presence of large peaks at 1560 and $780 \mathrm{~cm}^{-1}$. Further these peaks were absent in the chemically treated fiber spectrum because of the removal of lignin by alkali and acrylic acid treatments. It is observed that the peak at $1250 \mathrm{~cm}^{-1}$ disappears for alkali treated fibers. Alkali treatment had removed the waxy epidermal tissue, adhesive pectins and hemicellulose that unite fiber bundles to each other. The C-O-C symmetric glycosidic stretch at $1100 \mathrm{~cm}^{-1}$ arose from the polysaccharide component that was largely cellulose and appeared for both untreated and treated abaca fibers. It can be summarised that treatment with acrylic acid and alkali had removed most of the lignin and hemicellulose components. Further, the treatment had changed the hydrophilic nature of the fibers into more hydrophobic nature.

\section{Water absorption}

To measure the water absorption, the fiber was immersed in a water sample from various sources. After every $24 \mathrm{~h}$, the fiber was taken out and excess water on the fiber surface was removed before weighing. Three replicates were tested and the results were presented as an average of three. For both untreated and treated fibers, the percentage of water absorption increased initially with square root of immersion time before reaching a maximum. It also showed that the percentage of moisture uptake decreased with an immersion time. This is attributed to the fact that the initial and second absorption phases are governed respectively by the wetting of fibers and the capillary absorption process where the water diffuses into the fibers until reaching a maximum absorption. When the immersion time becomes significant, a decrease in the moisture absorption is due to the hydrophilic property of cellulosic fibers as more water molecules penetrate into the micro cracks present in these fibers, making the fibers swell and eventually leading to failure $^{46}$.

The study of the moisture absorption of untreated fiber showed that the untreated abaca fiber absorbs more moisture in sea water than in other water samples. The maximum moisture absorption of untreated abaca fiber was found to be $146.02 \%, 166.15 \%, 195.12 \%$, and $200.04 \%$ in pond water, river water, borewell water and sea water respectively. The moisture absorption by the fiber is due to the fact that abaca fiber contains a considerable amount of hemicellulose in its structure.

\section{Influence of esterification on water absorption}

The effect of esterification of abaca fiber on moisture absorption is presented in Figure 3. The water absorption study of esterified abaca fiber was determined at room temperature. Prior to the water absorption studies, the untreated abaca fiber was treated with 5, 10 and $15 \%$ sodium hydroxide solution and then treated with acrylic acid as mentioned in the experimental procedure. From Figure 3, it can be observed that the moisture absorption ability of abaca fiber was reduced drastically by acrylic acid treatment. Also, acrylic acid treated abaca fiber showed about 32.87, 32.53, 50.76 and 39.01\% lower moisture absorption than untreated fiber in pond water, river water, borewell water and sea water respectively. Further, the fiber treated with $15 \% \mathrm{NaOH}$ prior to the esterification showed the best results. The results obtained clearly point out that the esterification process decreased the dissemination of water into the fiber and fiber become more hydrophobic. This is due to the replacement of hydroxyl groups by hydrophobic ester groups. Chemical modification takes place as the acrylic acid substitute the cell wall hydroxyl groups with ester groups, making the surface more hydrophobic ${ }^{43,47}$. 


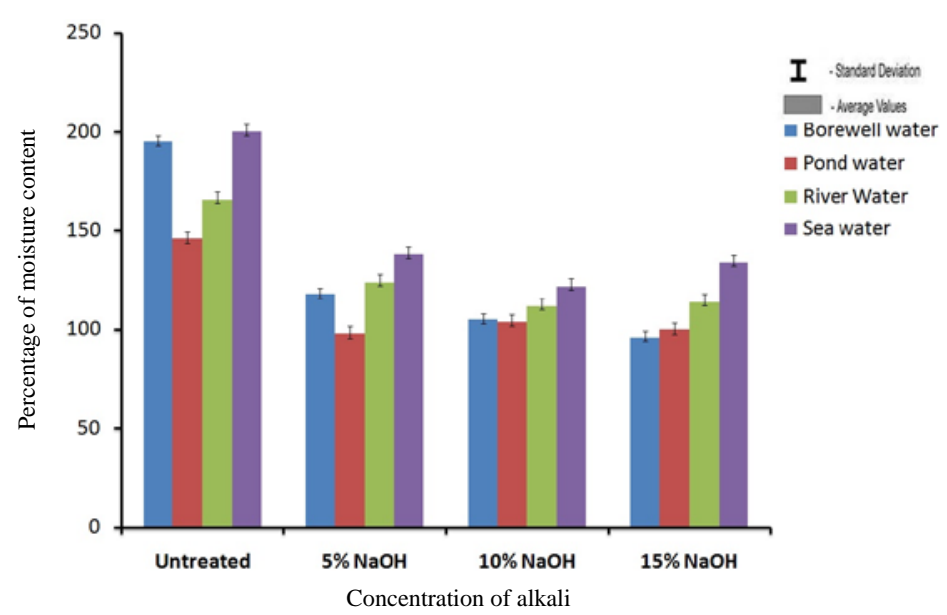

Figure 3. Comparison of moisture absorption studies of untreated and 5\% acrylic acid treated abaca fiber with 5\%, 10\% and $15 \% \mathrm{NaOH}$ pre-treatment

To summarise, natural fibers are made up of cellulose, hemicellulose and lignin. The cellulose is held together by amorphous hemicelluloses and fibers are cemented together in the plant by lignin. Lignocellulosics cell wall polymers contain hydroxyl and other oxygen containing groups that attract moisture through hydrogen bonding. The hemicellulose is mainly responsible for moisture absorption, but the accessible cellulose, noncrystalline cellulose, lignin and surface of crystalline cellulose also play major roles. Reduction in moisture uptake by the treated fiber may be due the partial removal of lignin and hemicellulose component of fiber by chemical treatment. Also, in all natural cellulose fibers, a hollow cavity called lumen exists in the unit cell of the fibers ${ }^{48}$. The hollow cavity generates more pathways for water to start diffusing into the fiber. The velocity of the diffusion process can be reduced by reducing the void content of the fiber. The cellular structure of the fiber is destroyed by the chemical treatment; hence reduced the void content and this in turn reduced the moisture uptake of treated fiber.

\section{Conclusion}

The potential of using natural fibers as reinforcing agents is based on the interfacial properties between fiber and polymer matrix. Also, the poor resistance of the fibers to water absorption can have undesirable effects on the structure, dimensional and mechanical properties of the natural fiber reinforced composites. It is possible to reduce the moisture absorption property of abaca fiber through its surface modification. The results presented in this work indicate that the abaca fiber treated with acrylic acid absorbs less moisture than the untreated.

\section{Acknowledgement}

The first author would like to thank the Management of KLE Society's BVB College of Engineering and Technology, Hubli, Karnataka, India for the kind encouragement and constant support provided. She sincerely thanks Prof. Ashok Shettar, Principal, KLE Society's BVB College of Engineering and Technology, without his encouragement and motivation, this work would not have been possible. The second author would like to thank Dr. M. Mohan Alva, Chairman, Alva's Education Foundation, for his kind encouragement and support provided. The third author would like to thank Sri G. M. Lingaraju, Secretary, GM Institute of Technology, Davangere, India, for their encouragement and support throughout this work. 


\section{References}

1. Sun R C, Tomkinson J, Wang Y X and Xiao B, Polymer, 2000, 41, 2647-2656.

2. Sain M and Panthapulakkal S, Ind Crops Products, 2006, 23, 1-8.

3. Pothan L A and Thomas S, Compos Sci Technol., 2003, 63, 1231-1240.

4. Gorenickx G, Pothan LA and Thomas S, Composites Part A: Appl Sci Manufacturing, 2006, 37(9), 1260-1269.

5. Ramadevi P, Dhanalakshmi S, Srinivasa C V and Basavaraju B, Bio Resour., 2012, 7(3), 3515-3524.

6. Srinivasa C V, Arifulla A, Goutham N, Santhosh T, Jaeethendra H J, Ravikumar R B Anil S C, Santhosh Kumar D G and Ashish J, Mater Design, 2011, 32(4), 2469-2475.

7. Dhanalakshmi S, Ramadevi P, Basavaraju B and Srinivasa C V, Int J Agriculture Sci., 2012, 4, 227-229.

8. Srinivasa C V, Basavaraju B, Kenchappa M G and Ranganagowda R P G, Bio Resources, 2010, 5(3), 1846-1858.

9. $\quad$ Aziz S H and Ansell M P, Composites Sci Technol., 2004, 64, 1219-1230.

10. Chow C P L, Xing X S and Li R K Y, Compos Sci Technol., 2007, 67, 306-313.

11. Gassan J and Bledzki A K, Compos Sci Technol., 1999, 59, 1303-1309.

12. Albuquerque A C de, Joseph K, Carvalho L H de and Almedia J R M, Compos Sci Technol., 2000, 60(6), 833-844.

13. Baley C, Composites Part A: Appl Sci Technol., 2002, 33, 939-948.

14. Arib R M N, Sapuan S M, Ahmad M M H M, Paridah M T and Zaman H M D K, Mater Design, 2006, 27(5), 391-396.

15. Coutts R S P and Ni Y, Cem Concr Compos., 1995, 17, 99-106.

16. Edeerozey A M Md, Adkhil H Md, Azhar A B and Ariffin M I Z, Mater Lett., 2007, 61, 2023-2025.

17. Vazquez A, Dominguez V A and Kenny J M, J Thermoplastics Compos Mater., 1999, 12(6), 477-497.

18. Jannah M, Mariatti M, Abu Bakkar A and Khalil A H P S, J Reinf Plast Compos., 2009, 28(12), 1519-1532.

19. Bledzki A K, Mamun A A and Faruk O, Xpress Polym Lett., 2007, 1(11), 755-762.

20. Joseph S, Sreekala M S, Oommen Z, Koshy P and Thomas S, Compos Sci Technol., 2002, 62, 1857-1868.

21. Bledzki A K, Faruk O and Sperber V E, Macromole Mater Eng., 2006, 291, 449-457.

22. Huang G, Mater Design, 2009, 30, 3931-3934.

23. Hintermann M, RIKO-2005, Hannover, Germany, 2005, 11.

24. Maya J J and Anandjiwala R D, Polym Compos., 2008, 29(2), 187-207.

25. Joseph K, Paul A and Thomas S, Compos Sci Technol., 1997, 57, 67-79.

26. Mishra S, Misra M, Tripathy S S, Nayak S K and Mohanty A K, Macromole Mater Eng., 2001, 286(2), 107-113.

27. Sreekala M S and Thomas S, Compos Sci Technol., 2003, 63, 861-869.

28. Seena J, Koshy P and Thomas S, Compos Interfaces, 2005, 12, 581-600.

29. Mishra S B and Luyt A S, Xpress Polym Lett., 2008, 2, 256-264.

30. Vilay M, Mariatti R, Mat T and Mitsugu T, Compos Sci Technol., 2008, 68, 631-638.

31. Panigrahi S, Li X and Tabil L, International Conference on Flax Other Bast Plants, 2008, ID number: 83.

32. Stana-Kleinschek K and Ribitsch V, Colloids and Surfaces A: Physicochemical and Engineering Aspects, 1998, 140, 127-138. 
33. Bismarck A, Mohanty A K, Askargorta I A, Czapla S, Misra M, Hinrichsen G and Springer J, Green Chem., 2001, 3(2), 100-107.

34. Jimenez A and Bismarck A, Cellulose, 2007, 14, 115-127.

35. Rout J, Misra M, Tripathy S S, Nayak SK and Mohanty A K, Compos Sci Technol., 2001, 61, 1303-1310.

36. Rowell R M, Young R A and Rowell J K, in the Paper and Composites from AgroBased Resources, CRC Press, New York, 1997, 105-131.

37. Rowell R M, Handbook of Wood Chemistry and Wood Composites, CRC Press, 2005

38. Indicula M, Boudene A, Umadevi L, Ibos L, Candau Y and Thomas S, Compos Sci Technol., 2006, 66(15), 2719-2725.

39. Taj S, Munawar M A and Khan S, Proceedings of Pakistan Academy of Science, 2007, 44(2), 129-144.

40. Satyanarayana K G, Sukumara K, Mukherjee P S, Pavithran C and Pillai S G K, Cem Concr Compos., 1990, 12(2), 117-136.

41. Prasad S V, Pavithran C and Rohtgi P K, J Mater Sci., 1983, 18, 1443-1454.

42. Bismarck A, Askargorta IA, Springer J, Lampke T, Wielage B, Stamboulis A, Shenderovich I and Limback HH, Polym Compos., 2002, 23, 872-894.

43. Bessadok, Marias S, Gouanve F, Colasse , Zimmerlin, I, Roudesli S and Metayer M, Compos Sci Technol., 2007, 67, 685-697.

44. Herrera-Franco P J and Valadez-Gonzalez A, Compos Part B: Eng., 2005, 36, 597-608.

45. Baley C, Busnel F, Grohens Y and Sire O, Composites Part A: Appl Sci Manufacturing, 2006, 37(10), 1626-1637.

46. Nosbi N, Akil H M, Ishak Z A and Abu baker A, BioResources, 2011, 6(2), 950-960.

47. Paul A, Joseph K and Thomas S, Compos Sci Technol., 1997, 57, 67-79.

48. Reddy N and Yang Y, Trends Biotechnol., 2005, 23(1), 22-27. 